\title{
Triangular fibrokartilaj kompleks yaralanmalarında artroskopik tedavi
}

\section{Arthroscopic treatment of triangular fibrocartilage complex injuries}

\author{
Uğur Bezirgan ${ }^{1}$, Mehmet Armangil ${ }^{2}$ \\ ${ }^{1}$ Ankara Bilkent Şehir Hastanesi, Ortopedi ve Travmatoloji, El Cerrahisi Kliniği, Ankara \\ ${ }^{2}$ Ankara Üniversitesi İbn-i Sina Hastanesi, Ortopedi ve Travmatoloji Ana Bilim Dalı, El Cerrahisi Bilim Dalı, Ankara
}

Triangular fibrokartilaj kompleksi (TFKK) el bileğinin ulnar köşesinde primer olarak distal radyoulnar eklemi sabitleyen ve aynı zamanda ulnokarpal eklem için şok abzorbe edici rolü olan iyi tanımlanmış bir anatomik oluşumdur. Ekstansör karpi ulnaris (EKU) tendonu için de önemli bir 'pulley' görevi vardır. TFKK ulnar karpus ile distal ulna arasında bulunan kartilajinöz ve ligamentöz bir yapıdır. Bu kompleksi fibrokartilaj bir disk, dorsal ve volar radyoulnar bağlar, ulnokarpal bağlar, menisküs benzeri bir yapı ve EKU tendonu derin kılıfı oluşturur. TFKK travmatik ve dejeneratif yırtıkları el bileği ulnar taraf ağıısnın en önemli nedenidir. Bu yaralanmalar başlangıçta ağrı kesiciler, steroid enjeksiyonları, atelleme ve günlük aktivitelerin düzenlenmesiyle tedavi edilmektedir. Konservatif tedaviye yanıt alınamayan olgularda artroskopik tedavi altın standarttır. Artroskopik cerrahi tedavi yaralanma tipine göre değişir. Genel olarak debridman, tamir, ulnar kısaltma ve Wafer ameliyatları olarak sınıflandırılmaktadır. Günümüzde el bileği artroskopik anatomisinin daha iyi anlaşılması, artroskopik cerrahi aletlerin, ekipmanların gelişmesi ve cerrahların becerisi sayesinde ağrı verici olan ulnar köşe (TFKK) yaralanmaları günü birlik cerrahiyle tedavi edilebilmektedir.

Anahtar sözcükler: triangular fibrokartilaj kompleks yırtığı; TFKK yırtı̆̆ı; artroskopik tamir; Wafer

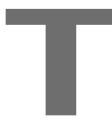

riangular fibrokartilaj kompleksi (TFKK) lunat, trikuetrum ve ulna başı arasında yük taşıyan bir anatomik yapıdır. El bileğinin ulnar tarafı ve distal radyoulnar eklem (DRUE) için primer sabitleyici bir görevi vardır. ${ }^{[1]}$ Palmer ve Werner TFKK'nin anatomik ayrıntılarını ve el bileğindeki biyomekanik rolünü ilk defa açıklayan bilim insanlarıdır. TFKK fibrokartilaj disk, radius ve ulnayı birbirine bağlayan dorsal ve palmar bağlar, ulnokarpal bağlar, menisküs homoloğu ve el bileği ulnar ekstansörünün alt kılıfından oluşur
Triangular fibrocartilage complex (TFCC) is a well-defined anatomical formation at the ulnar corner of the wrist that primarily stabilizes the distal radioulnar joint and also has a shock absorbing role for the ulnocarpal joint. It also has an important 'pulley' function for the extensor carpi ulnaris (ECU) tendon. TFCC is a cartilaginous and ligamentous structure located between the ulnar carpus and the distal ulna. This complex consists of a fibrocartilaginous disc, dorsal and volar radioulnar ligaments, ulnocarpal ligaments, a meniscus-like structure and the deep sheath of the ECU tendon. TFCC traumatic and degenerative tears are the most important causes of ulnar wrist pain. These injuries are initially treated by NSAIDs, steroid injections, splinting and modification of daily activities. Arthroscopic treatment is the gold standard in cases that do not respond to conservative treatment. Arthroscopic surgical treatment depends on the type of injury pattern. It is generally classified as debridement, repair, ulnar shortening and Wafer surgeries. Today, painful ulnar corner (TFCC) injuries can be treated with an outpatient surgery thanks to a better understanding of the wrist arthroscopic anatomy, the development of arthroscopic surgical instruments and equipment and the dexterity of surgeons.

Key words: triangular fibrocartilage complex tear; TFCC tear; arthroscopic repair; Wafer

(Şekil 1). Bu bölgenin karışık anatomisi ve kompleks yük aktarımı kinematiği nedeniyle yıpranmaya ve yaralanmaya yatkın hale gelmektedir. TFKK'deki travmatik ve dejeneratif hasarlar özellikle ön kol rotasyonuyla belirsiz ulnar taraflı el bilek ağrısı ile kendini gösterir.

Manyetik rezonans (MR) görüntüleme ilk tanısal araç olmakla birlikte tanıda altın standart artroskopidir. Tedavi seçeneklerinde ilk başta splint, non-steroid anti-enflamatuvar ilaç ve steroid enjeksiyonlarından sonuç alınamazsa artroskopik cerrahi yer almaktadır.

\footnotetext{
- Illetişim adresi: Op. Dr. Uğur Bezirgan, Ankara Bilkent Şehir Hastanesi, Ortopedi ve Travmatoloji, El Cerrahisi Kliniği, Üniversiteler Mahallesi 1604. Cadde No: 9, 06800 Çankaya, Ankara Tel: 0553 - 4768047 e-posta: ugurbezirgan@gmail.com
} 


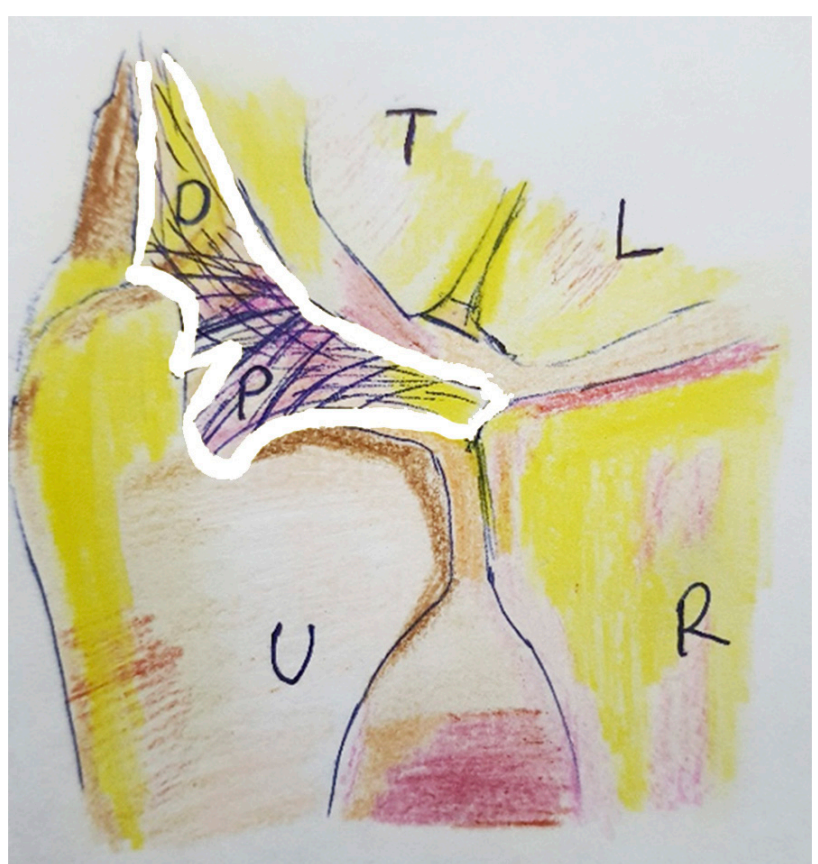

Şekil 1. Triangular fibrokartilaj kompleksinin (TFKK) distal ve proksimal komponentinin gösterildiği histolojik kesitin temsili çizimi. Beyaz çizgi TFKK sınırlarıdır (U, ulna; R, radius; T, trikuetrum; L, lunatum; D, distal; P, proksimal).

\section{Etiyopatogenez}

El bileği ulnar deviasyonda iken yüklenme ve yük transferi ile yaralanma meydana gelir. Zorlayıcı ulnar deviasyon raket veya sopayı pronasyonda kuvvetli sallama sonucu gelişir. Pozitif ulnar varyans, ulnanın eklem yüzeyinin radiusun lunat fossa denilen eklem yüzeyinin daha distalinde yer almasından kaynaklanır ve TFKK yaralanmasıyla ilişkilidir.

Artan yaşla birlikte TFKK hasarı riski artmaktadır. Yetmiş yaş ve üzerinde $\% 49$ sıklıkta ve 30 yaş ve altında \%27 sıklıkta görülmektedir. ${ }^{[2]}$ Bir çalışmada bütün TFKK yaralanmalarında el bileği ulnar köşe ağrısı olmadığı gösterilmiştir. ${ }^{[3]}$

Ulnar varyans supinasyonla azalmakta ve pronasyonla artmaktadır. Ulnanın uzunluğundaki küçük değişiklikler bile ulnaya yüklenme miktarında önemli bir etkiye sahiptir. ${ }^{[4]}$

Ekstansör karpi ulnaris (EKU) tendonu adeta TFKK'ye yaslanarak hareket etmektedir. Bu nedenle EKU hareketindeki bir değişiklikle TFKK üzerine anormal bir kuvvet uygulanması sonucu TFKK yaralanması ile sonuçlanabilir. ${ }^{[5]}$

Triangular fibrokartilaj kompleksi diskinin kollajen lifleri sadece periferde vaskülerdir. Bu nedenle sadece periferik yırtıkların tamir edilmesi iyileşme ile sonuçlanır. Distal radiusu ulnaya volarden ve dorsalden bağlayan ligamentler oldukça güçlüdür ve sıkıca biraraya gelmiş paralel oryantasyonlu kollajen lif demetlerinden oluşmuştur. Bu bağlar distal radyoulnar eklemin güçlü bir sabitleyicisidir. ${ }^{[6]}$

\section{Değerlendirme}

Hastalar genellikle kapı kolunu açma ve kavanoz kapağını çevirme gibi ön kolun rotasyonel hareketleri ile el bileğinin ulnar tarafında ağrı tarif eder. Ağrıya kavrama güçlüğü, instabilite ve ulnar taraflı tıklama eşlik edebilir. Muayeneye TFKK'yi ulna başının distalinde ulnar stiloid, fleksör karpi ulnaris (FKU) ve pisiform arasındaki yumuşak noktada palpe ederek başlanır. Ulnar fovea belirtisi olarak isimlendirilen bu test oldukça duyarlı (\%95) ve özgüldür (\%86). Ulnotrikuetral bağ ve TFKK foveal bağlantı yırtığını göstermede oldukça güvenilir bir testtir. Piyano tuşu testi ön kol supinasyonda el sabitlenip ulna başı volare itilerek değerlendirilir ve distal radyoulnar eklem (DRUE) stabilitesini ölçmekte kullanılır. Ulnanın deplasman miktarının karşı tarafla kıyaslanmasında yarar vardır çünkü genel bağ esnekliği olan hastalarda önemli miktarda deplasman görülebilir.

İlk başta kırığı ve ulnar varyansı değerlendirmek için röntgen filmi çekilir. Sonrasında manyetik rezonans (MR) veya MR artrografi çekilir (Şekil 2). MR artrografi yırtığı değerlendirmede sadece MR'ye göre biraz daha iyidir ancak hasta konforsuzluğu ve maliyetinin yüksekliği nedeniyle sıklıkla tercih edilmemektedir. ${ }^{[7]}$

Lunotrikuetral bağda yaralanma olup olmaması tedaviyi belirlemede çok önemlidir. MR artrografide kontrastın araya girmesiyle kesin olarak tanınır. Böyle bir yaralanma röntgende skafoid ve lunatın volar tilti ile de anlaşılabilir.

\section{Tedavi}

Distal radyoulnar eklem instabilitesi olmadığı sürece hastalarda altı ay süreyle konservatif tedavi denenebilir. Konservatif tedavi dışında son zamanlarda geliştirilen kısa bir breysle elde edilen sonuçlar oldukça umut vericidir. Bu breys bir yıllık kullanım sonucunda üst ekstremitede devamlı bir iyileşme göstermiştir. ${ }^{[8]}$

Cerrahi seçenekler ise artroskopik tamir, artroskopik debridman, ulnar kısaltma ve Wafer prosedürünü içermektedir.

Cerrahi tedavi yaralanmanın Palmer sınıflamasına göre düzenlenmiştir. ${ }^{[9]}$ Ancak 35 hastada yapılan bir çalışmada Estrella ve ark., \%51 oranında EKU ile ekstansör dijiti minimi (EDM) tendonlarının altında Palmer'in tarif etmediği bir bölgede dorsal TFKK yırtığına rastlamışlardır (Şekil 3). ${ }^{[10]}$ 

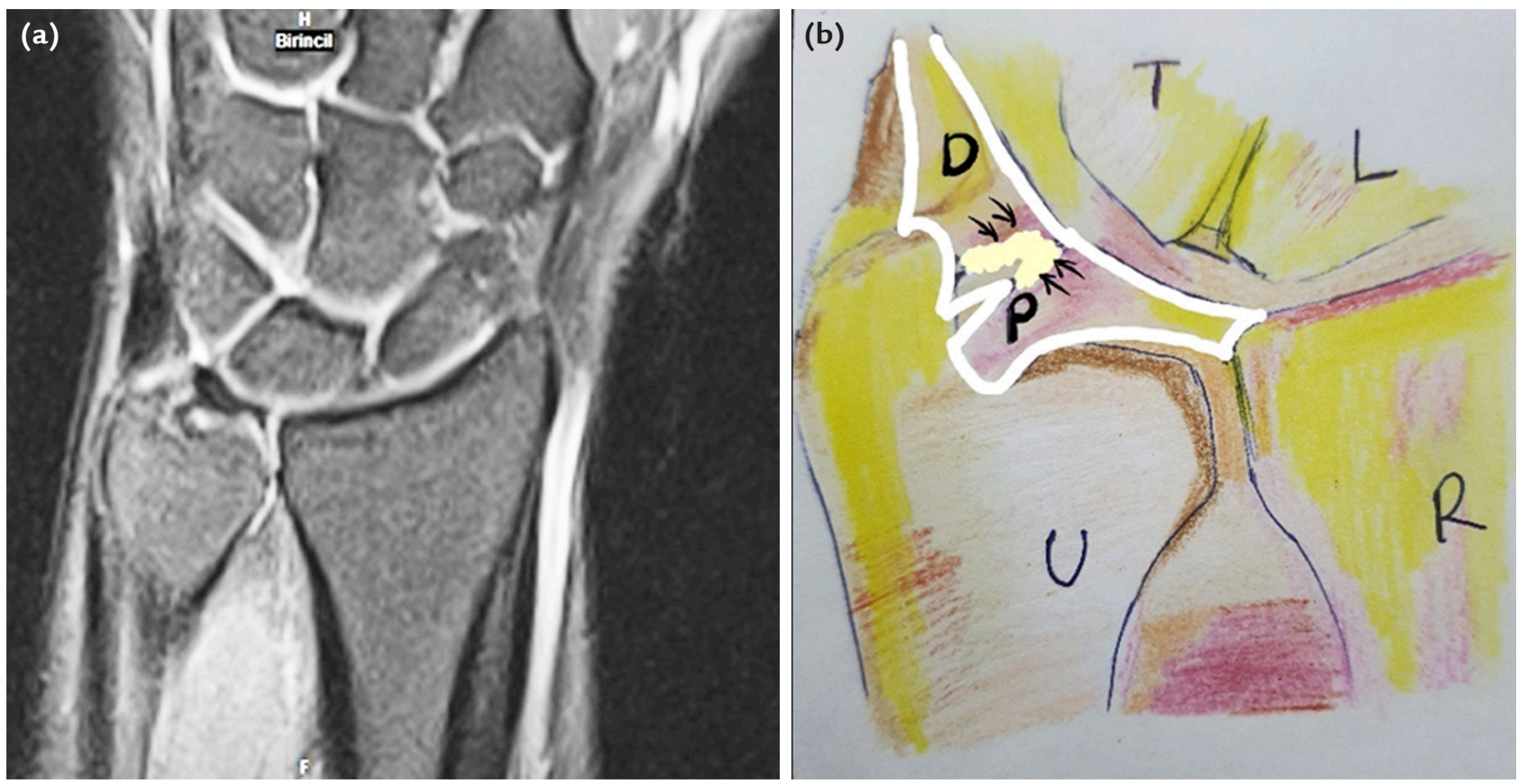

Şekil 2. a, b. Manyetik rezonansta (MR'de) triangular fibrokartilaj kompleks (TFKK) diskinde periferik yırtık ve diyagramı görülmektedir (a). Diyagramda siyah oklar periferik ulnar yırtığı göstermektedir (U, ulna; R, radius; T, trikuetrum; L, lunatum; D, distal; P, proksimal) (b).

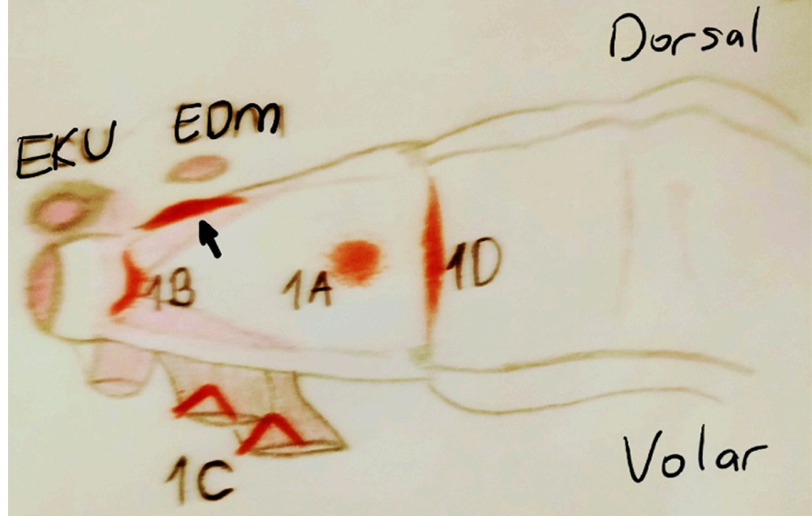

Şekil 3. Sıklıkla gözlenen dorsal koronal yırtık paternine (siyah oklar) Palmer sınıflamasında yer verilmemiştir (EKU, ekstansör karpi ulnaris; EDM, ekstansör dijiti minimi; 1A, santral yırtık; 1B, periferik ulnar yırtık; 1C, ulnokarpal bağlarda yırtık; 1D, radyal yırtık).

Tip 1A: Bu yaralanma diskin avasküler santral bölgesinde olduğundan artroskopik debridman ile tedavi edilir. Diskteki stabil olmayan flepler sinovit ve eklemde takılma yapabildiğinden tıpkı menisküs yırtığında olduğu gibi stabil bir kenar elde edilene dek tıraşlanmalıdır. Radyoulnar instabiliteyi önlemek için dorsal ve volar radyoulnar bağlar tıraşlanma esnasında korunmalıdır. Diskin \%80 kadarı instabilite oluşmadan tıraşlanabilmektedir.

\section{Artroskopik debridman tekniği}

Standart el bileği artroskopisi tekniğiyle 3-4 portalinden TFKK görüntülenir. Diskteki gevşeklik 4-5 veya $6 \mathrm{R}$ portalinden bir prob yardımıyla test edilir (trambolin testi). Periferik bir yırtıkta derin liflerin sağlamlığını ölçmek için ayrıca kanca testi yapılır. Debridman 2.0-3.0 tıraşlayıcı ile yapılır. Ulna pozitif varyansı olan hastalarda debridman yeterli olmaz. Bu hastalarda ilave olarak ulnar kısaltma osteotomisi yapmak gerekir. ${ }^{[11]}$

Tip 1B: Vaskülaritesi iyi olduğundan direkt cerrahi tamir seçeneklerine odaklanılan bir bölgedir. TFKK proksimal yırtıkları, distal yırtıklardan DRUE ve karpal sabitleyici olması nedeniyle ayrılır. Distal yırtıklar stabildir ve artroskopik kapsüler periferik sütürle tamir edilir. Eğer TFKK ulnar foveadan tamamen ayrıldıysa proksimal yırtıklardır. Proksimal yırtıklarda radyoulnar bağlarda yaralanma vardır ve bu yırtıklar instabildir. TFKK retrakteyse veya bir yıldan uzun süre semptomu olan hastaların kronik yırtıklarda tendon grefti ile rekonstrüksiyon gerekebilir. Rekonstrüksiyon düşünülen olgularda DRUE artriti olmadığından emin olunmalıdır. Foveal yırtıkların kemiğe tespit edilmesi gerekir ve tespitinde transosseöz dikişler veya mini çapa sütürler kullanılır. 


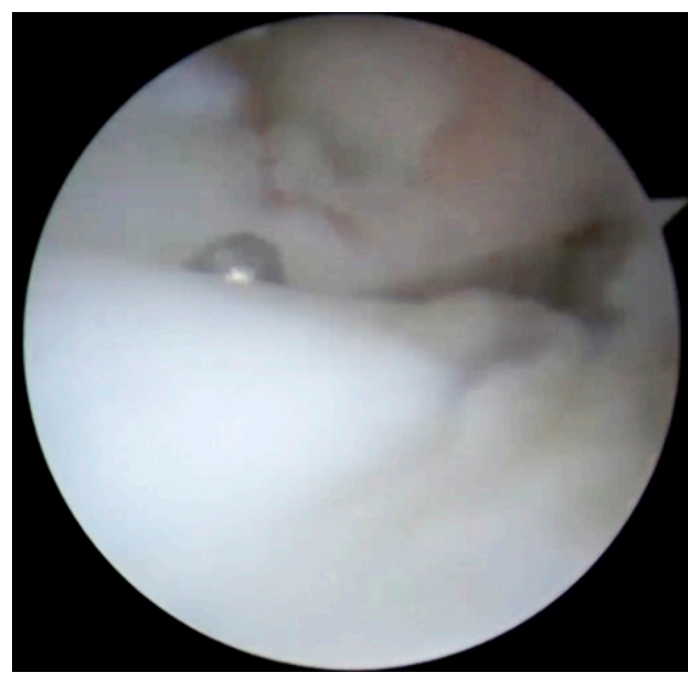

Şekil 4. Trambolin testinde prob ile triangular fibrokartilaj kompleks (TFKK) diskine basınca sallanma hareketi olması periferik bir yırtığın göstergesidir.

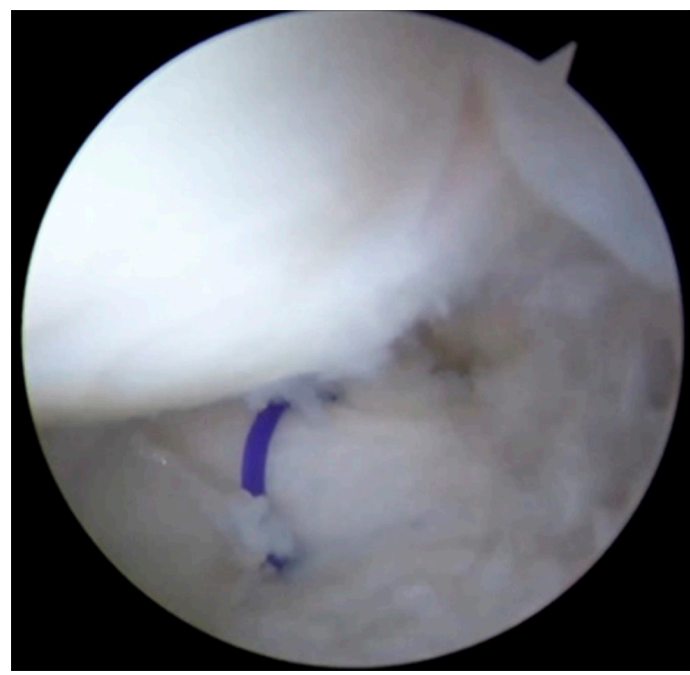

Şekil 6. Sütürlerden biri transfer edildikten sonra kapsülden ve triangular fibrokartilaj kompleks (TFKK) diskinin içinden geçen horizontal matris dikiş görülmektedir.

\section{Artroskopik kapsüler tamir tekniği}

Standart el bilek artroskopi portalleri açıldıktan sonra trambolin ve kanca testleri yapılır. Trambolin testinde diske prob ile bastırmakla sallanma hareketi olması pozitiftir (Şekil 4). Kanca testinde prob ile distal TFKK kaldırılmaya çalışılır. Traksiyona direncin kaybolması pozitif olarak değerlendirilir. Tıraşlayıcı ile yırtık disk debride edilip kanlandırıldıktan sonra $6 U$ portalinden küçük longitudinal bir kesi yapılır. Ulnar sinirin duyu dalları askıya alınarak güvenli bir kapsüler tamir bölgesi açılır. $6 \mathrm{U}$ portalinden 20G iğne ile 2.0 PDS sütür

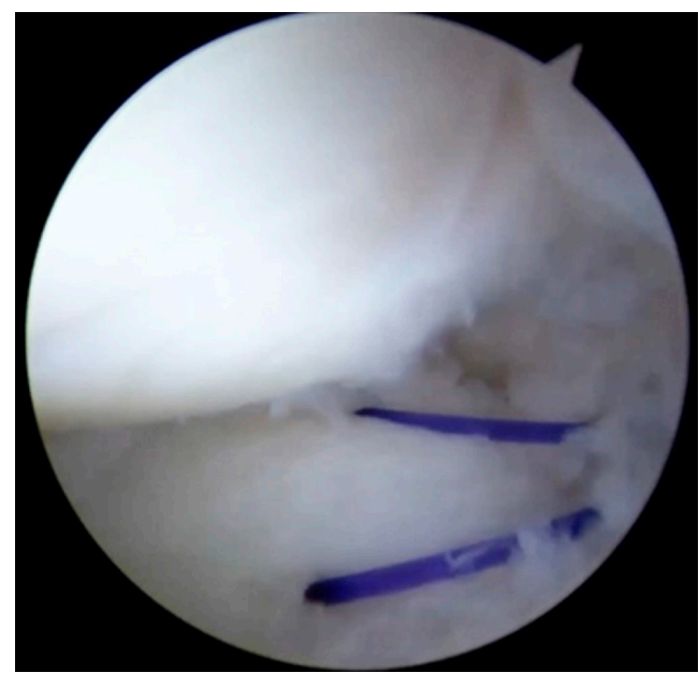

Şekil 5. İlmek oluşturmadan önce $6 U$ portalden geçilen iki adet sütür görülmektedir.

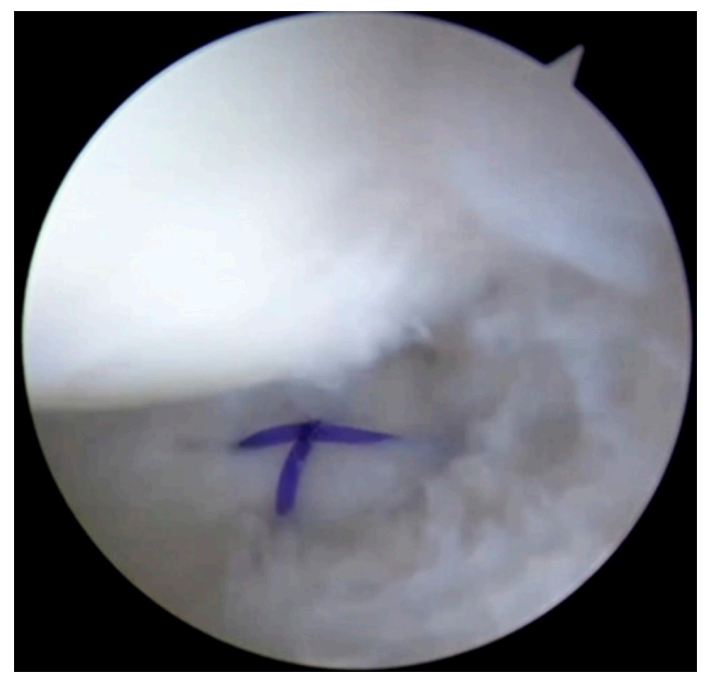

Şekil 7. İkinci bir dikiş geçildikten sonra traksiyon gevşetilip sütürler el bilek supinasyon ve ekstansiyonda bağlanmıştır. Triangular fibrokartilaj kompleks (TFKK) diskinin tamir sonrası gergin olduğu görülmektedir.

diskten geçerek $6 \mathrm{R}$ veya $4-5$ portale taşınır. İkinci bir iğne ile aynı geçiş yapılır (Şekil 5). Aynı portaldeki sütürlerden biriyle ilmek oluşturulur. Diğer sütür bu ilmeğe bağlanır ve 4-5 veya $6 R$ 'den $6 U$ portale transferi yapılır. Böylece horizontal matris dikiş diskin içinden ve kapsülden geçmiş olur (Şekil 6). Yırtığın genişliği fazla ise bu şekilde iki veya üç dikiş geçilebilir. Traksiyon gevşetildikten sonra el bilek supinasyon ve hafif ekstansiyonda sütürler bağlanır (Şekil 7). Hastalar üç hafta uzun kol atelde ve sonrasında üç hafta kısa kol atelde takip edildikten sonra rehabilitasyona başlarlar. 


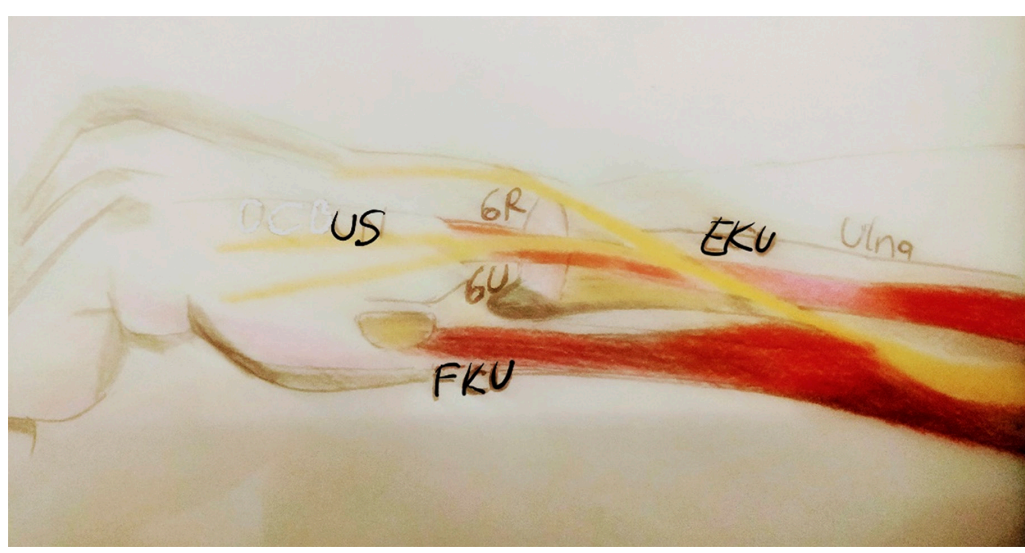

Şekil 8. Ulnar sinirin dorsal duyu dalları $6 U$ ve derin foveal portale oldukça yakın seyrettiğinden portal açarken bu bölgede biraz geniş bir longitudinal kesi yapılması ameliyat sonrası nöropatik ağrıyı önlemede önemlidir (US, ulnar sinir [dorsal duyusal dalları]; EKU, ekstansör karpi ulnaris; FKU, fleksör karpi ulnaris).

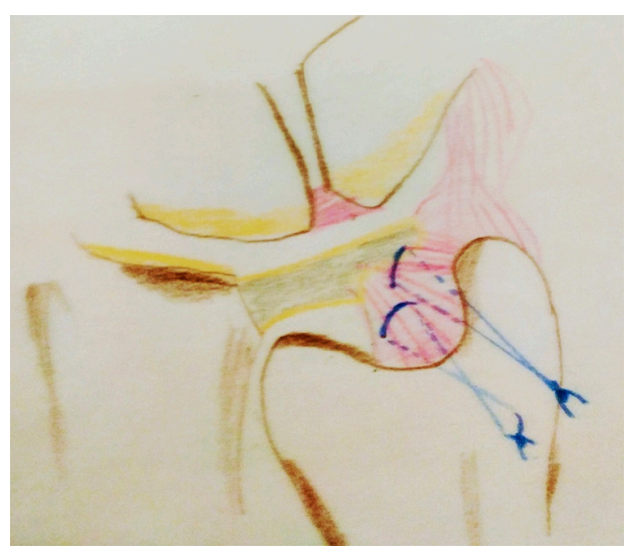

Şekil 9. Transosseöz triangular fibrokartilaj kompleks (TFKK) tamiri diyagramı.

\section{Artroskopik transosseöz tamir tekniği}

Öncelikle ideal foveal tamir için eklem dışı olan EKU tendonu ve kılıfında bir patoloji olmamalıdır. Transosseöz tamir planlamak için genel anestezi altında DRUE instabilitesinin ortaya konması gerekir. Artroskopide trambolin bulgusu ve pozitif kanca testinin olması TFKK'nın foveadan ayrıldığını destekler. Distal ulnanın ulnar kenarından cilt kesisi yapılır. $6 \mathrm{U}$ portali dikiş giriş yerleri ulnar sinirin dorsal duyu dalına 1,9-2,7 mm mesafede bulunmuştur. ${ }^{[12,13]}$ Ulnar sinirin duyu dalları (Şekil 8) korunarak foveal yapışma yeri küretle kanayıncaya dek tazelenir. Ulnar stilodin $1 \mathrm{~cm}$ proksimalinden ön kol nötral rotasyonda 1,4 K-teliyle iki delik foveal yapışma yerinden açılır. Bu aşamada küçük eklem artroskopi hedef alma aleti kullanılarak karpal kemiklerin kıkırdağının zarar görmesi de önlenmiş olur. 16G iğne ile 2.0 PDS sütürler TFKK diskinden geçirilir; 4-5 veya $6 \mathrm{R}$ portaline alınan sütürlerin birinden ilmek oluşturularak diğer sütür bağlanır ve ulnar sınırdaki tünelden çekilir. Böylelikle kemik tünellerden geçen sütürler horizontal matris şeklinde kemik üzerinde el bilek supinasyonda ve hafif ekstansiyonda bağlanır (Şekil 9). Ek olarak kapsüler tamir tekniğinde anlatıldığı gibi yüzeyel dikişler de geçilebilir. Rehabilitasyon kapsüler tamir tekniğinde anlatıldığı gibidir.

Artroskopik tamirde tatmin edici olmayan kötü sonuçlar ileri yaşta ve pozitif ulnar varyansı olan hastalarda gözlenmiştir. ${ }^{[14]}$

Tip 1C: Bu yırtıklar genellikle vertikal yırtıklardır ve artroskopik plikasyonla tamir edilmeye çalışılır.

Tip 1D: Radyoulnar bağ hasarı da varsa tamir edilmelidir.
Tip 1D yırtıkların açık tamiri teknik olarak oldukça zordur. ${ }^{[15]}$ Bu tip yırtıklarda 4.-5. ekstansör kompartmanların arasından dorsal ulnar insizyon yapılır. Ulnokarpal eklem kapsülü TFKK'ye paralel olarak disseke edilir. Ardından kapsüler kesi proksimale uzatılarak radyoulnar bağlar sigmoid çentikten kaldırılır. Radyokarpal ekleme bir lamina ayırıcı yerleştirilir. Radiusa yerleştirilen mini sütür ankor ile diskten geçen sütürler uygun pozisyonda bağlanır. Dorsal radyoulnar bağ distal radiusun ulnar kenarına anatomik olarak tespit edilir. Geniş bir yırtığa bağlı ciddi instabilite varlığında distal radyoulnar eklemin proksimalinden K-telleriyle transfiksasyon yapılabilir.

Distal radius kırığına bu tipte yırtık eşlik ediyorsa debridman sonrası K-teli ile tespit de yapılabilir.

Tip 2 lezyonların tedavisinde lunotrikuetral bağın sağlam olup olmaması önemlidir. 2A-2B-2C'de konservatif tedaviye cevap alınmadıysa hastalar artroskopik ulna başının distal yüzün tıraşlanması (Wafer) girişiminden yarar görür. 2D grubundaki hastalarda lunotrikuetral bağ yaralanması vardır ve bu hastalara ulnar kısaltma osteotomisi yapılır. 2E'de ulnokarpal artrit geliştiğinden ulna başının çıkarılması düşünülebilir.

\section{Artroskopik Wafer prosedürü}

Standart 3-4 giriş portali ve 4-5 veya $6 \mathrm{R}$ çalışma portalleri açılır. TFKK diskinin santraldeki geniş bir parçası debride edilir. Bu aşamada volar ve dorsal radyoulnar ligamentleri ve ulnar stiloiddeki TFKK yapışma bölgesini bozmamaya özen gösterilmelidir. Ulna başı kıkırdağı subkondral kemiğe kadar $2 \mathrm{~mm}$ traşlayıcı ile temizlenir. Traksiyon altında pasif ön kol rotasyonu ile yeterli ve yekpare bir temizlik gerçekleştirilir. Subkondral kemik 
üzerindeki bütün kaba yüzeyler tıraşlayıcı ile düzeltilmelidir. Artroskop aralıklı olarak çalışma portaline de alınarak yeterli eksizyonun yapılıp yapılmadığı kontrol edilmelidir. Bu cerrahiden bir hafta sonra hareket başlanabilir ve güçlendirme egzersizlerine iki hafta sonra geçilebilir.

\section{KAYNAKLAR}

1. Kleinman WB. Stability of the distal radioulna joint: Biomechanics, pathophysiology, physical diagnosis, and restoration of function what we have learned in 25 Years. J Hand Surg Am 2007;32(7):1086-106. Crossref

2. Chan JJ, Teunis T, Ring D. Prevalence of triangular fibrocartilage complex abnormalities regardless of symptoms rise with age: Systematic review and pooled analysis. Clin Orthop Relat Res 2014;472(12):3987-94. Crossref

3. Roh YH, Kim S, Gong HS, Baek GH. Prevalence and clinical characteristics of radiographic central triangular fibrocartilage complex tears in symptomatic and asymptomatic individuals younger than 50 years. Arch Orthop Trauma Surg 2018;138(8):1173-8. Crossref

4. Palmer AK, Werner FW. Biomechanics of the distal radioulnar joint. Clin Orthop Relat Res 1984;(187):26-35. Crossref

5. Tang JB, Ryu J, Kish V. The triangular fibrocartilage complex: An important component of the pulley for the ulnar wrist extensor. J Hand Surg Am 1998;23(6):986-91. Crossref

6. Semisch M, Hagert E, Garcia-Elias M, Lluch A, Rein S. Histological assessment of the triangular fibrocartilage complex. J. Hand Surg Br 2016;41(5):527-33. Crossref
7. Boer BC, Vestering M, Van Raak SM, van Kooten EO, Huis $\mathrm{R}$, Vochteloo $\mathrm{AJH}$. MR arthrography is slightly more accurate than conventional MRI in detecting TFCC lesions of the wrist. Eur J Orthop Surg Traumatol 2018;28(8):1549-53. Crossref

8. Barlow SJ. A non-surgical intervention for triangular fibrocartilage complex tears. Physiother Res Int 2016;21(4):271-76. Crossref

9. Skalski MR, White EA, Patel DB, Schein AJ, RiveraMelo $\mathrm{H}$, Matcuk Jr GR. The traumatized TFCC. An illustrated review of the anatomy and injury patterns of the triangular fibrocartilage complex. Curr Probl Diagn Radiol 2016;45(1):39-50. Crossref

10. Estrella EP, Hung LK, Ho PC, Tse WL. Arthroscopic repair of triangular fibrocartilage complex tears. Arthroscopy 2007;23(7):729-37, 737.e1. Crossref

11. Hulsizer D, Weiss APC, Akelman E. Ulna-shortening osteotomy after failed arthroscopic debridement of the triangular fibrocartilage complex. J Hand Surg Am 1997;22(4):694-8. Crossref

12. McAdams TR, Hentz VR. Injury to the dorsal sensory branch of the ulnar nerve in the arthroscopic repair of ulnar-sided triangular fibrocartilage tears using an inside-out technique: A cadaver study. J Hand Surg Am 2002;27(5):840-4. Crossref

13. Slutsky DJ. Arthroscopic evaluation of the foveal attachment of the triangular fibrocartilage. Hand Clin 2011;27(3):25561. Crossref

14. Ruch DS, Papadonikolakis A. Arthroscopically assisted repair of peripheral triangular fibrocartilage complex tears: Factors affecting outcome. Arthroscopy 2005;21(9):1126-30. Crossref

15. Cooney WP, Linscheid RL, Dobyns JH. Triangular fibrocartilage tears. J Hand Surg Am 1994;19(1):143-54. Crossref 